\title{
IDENTIFIKASI JENIS ROTAN DI KAWASAN HUTAN ADAT DUSUN ENSIBAU DESA SEMIRAU KECAMATAN JANGKANG KABUPATEN SANGGAU
}

\author{
(Identification Of Rattan In The Forest Area Of The Ensibau Flower, Semirau Village, \\ Jangkang District, Sanggau District)
}

\author{
Nobertus Geat Saputra, M. Idham, Ahmad Yani. \\ Fakultas Kehutanan Universitas Tanjungpura Jl. Daya Nasional, Pontianak 78124 \\ E-mail: geatsaputra@gmail.com
}

\begin{abstract}
Rattan in trade is generally called rattan, which is a typical tropical plant and is classified as familipalmae, including climbing plant species that require a host tree for its growth process. States that when compared with plants from other palma tribes, rattan has a variety of uniqueness, among others, the length of the stem reaches $100 \mathrm{~m}$ or more even though the diameter is only as big as the mother or toe, in terms of shape, rattan plants are not attractive because in part big wrapped in sharp thorny midribs. Rattan stems have extraordinary tenacity and flexibility. Because of that tenacity and flexibility, rattan sticks can be made in various forms of household furniture or other ornaments such as chairs, baskets, and so on. Especially for rattan, in West Kalimantan there are types of rattan with high economic value such as: rattan saga, branch rattan, and ring rattan. From the survey data on rattan inventory from 1990 to 2010, the distribution of rattan in West Kalimantan is generally in swamp forests and part of dryland forest. The Adat Ensibau Forest Area also has a high level of biodiversity, one of which is non-timber forest products, namely rattan. An increase in the number of people that occur around the Adat Ensibau Huatan Area is one of the causes of the emergence of pressure on the preservation of existing types of rattan, so that it will raise concerns or decrease the potential of rattan in the future.
\end{abstract}

Keywords : customary forest, Ensibau hamlet, identification, rattan.

\section{PENDAHULUAN}

Hutan merupakan komunitas biotik dari suatu ekosistem yang hidup dan tumbuh secara dinamis, yang dapat menjaga kesuburan tanah, kelestarian tata air, makhuk hidup, tumbuahan dan plasma nutfa. Di dalam hutan terdapat struktur yang kompleks menciptakan lingkungan sedemikian rupa, sehingga memungkinkan keanekaragaman jenis mahluk hidup dan tumbuan yang dapat hidup di dalamnya. Salah satu dari keanekaragaman jenis yang terdapat tumbuh dengan baik di hutan Indonesia adalah rotan. rattan adalah tumbuhan khas tropika dan tergolong familipalmae, termasuk dalam spesies tumbuhan pemanjat yang memerlukan pohon inang untuk proses pertumbuhannya rotan memiliki berbagai keunikan antara lain panjang batang mencapai $100 \mathrm{~m}$ atau lebih walaupun diameternya hanya sebesar ibu jaritangan atau ibu jari kaki, dari segi bentuknya, tanaman rotan memang tidak menarik karena sebagian besar terbalut pelepah yang berduri tajam. 
Penelitian ini bertujuan untuk mengidentifikasi jenis rotan yang terdapat di kawasan Hutan Adat Dusun Ensibau Desa Semirau Kecamatan Jangkang Kabupaten Sanggau.

Penelitian ini diharapkan dapat memberikan manfaat berupa informasi mengenai jenis-jenis rotan yang terdapat di kawasan Hutan Adat Dusun Ensibau Desa Semirau Kecamatan Jangkang Kabupaten Sanggau dalam pemanfaatan dan pelestarian jenis-jenis rotan.

\section{METODE PENELITIAN}

Penelitian ini dilaksanakan di Kawasan Hutan Adat Dusun Ensibau Desa Semirau Kecamatan Jangkang Kabupatan Sanggau dengan lama penelitian 4 (empat) minggu efektif di lapangan.

\section{Alat dan Objek Penelitian}

Alat dan bahan yang digunakan dalam penelitian adalah peta lokasi, alat tulis, thally sheet, GPS, altimeter, kaliper, meteran atau penggaris, parang, tali rapia, kamera, buku untuk indentifikasi jenis-jenis rotan.
Objek dalam penelitian ini adalah semua jenis rotan yang terdapat pada petak pengamatan.

\section{Metode Pengambilan Data}

Penelitian ini dilaksanakan menggunakan metode eksplorasi dengan teknik purposive sampling berupa petak. Adapun petak contoh yang dibuat dalam teknik purposive sampling ini berupa petak ganda dengan pertimbangan banyaknya jumlah jenis rotan. penggunaan petak berukuran $5 \mathrm{~m}$ $\mathrm{x} 5 \mathrm{~m}$ untuk lapisan vegetasi tingkat bawah. Objek dalam penelitian ini adalah semua jenis rotan yang terdapat pada petak pengamatan.

\section{HASIL DAN PEMBAHASAN}

\section{Komposisi Jenis Rotan}

Hasil pengamatan dan identifikasi lapangan dengan menggunakan metode eksplorasi, pada teknik purposive sampling dilapangan, Kecamatan Jangkang dikawasan hutan adat Dusun Ensibau, ditemukan 7 jenis rotan yang tergolong dalam 3 genus, hal ini dapat dilihat pada tabel 5 berikut ini.

Tabel 5. Daftar jenis rotan yang ditemukan pada petak pengamatan (List of types of rattan found in the observation plots)

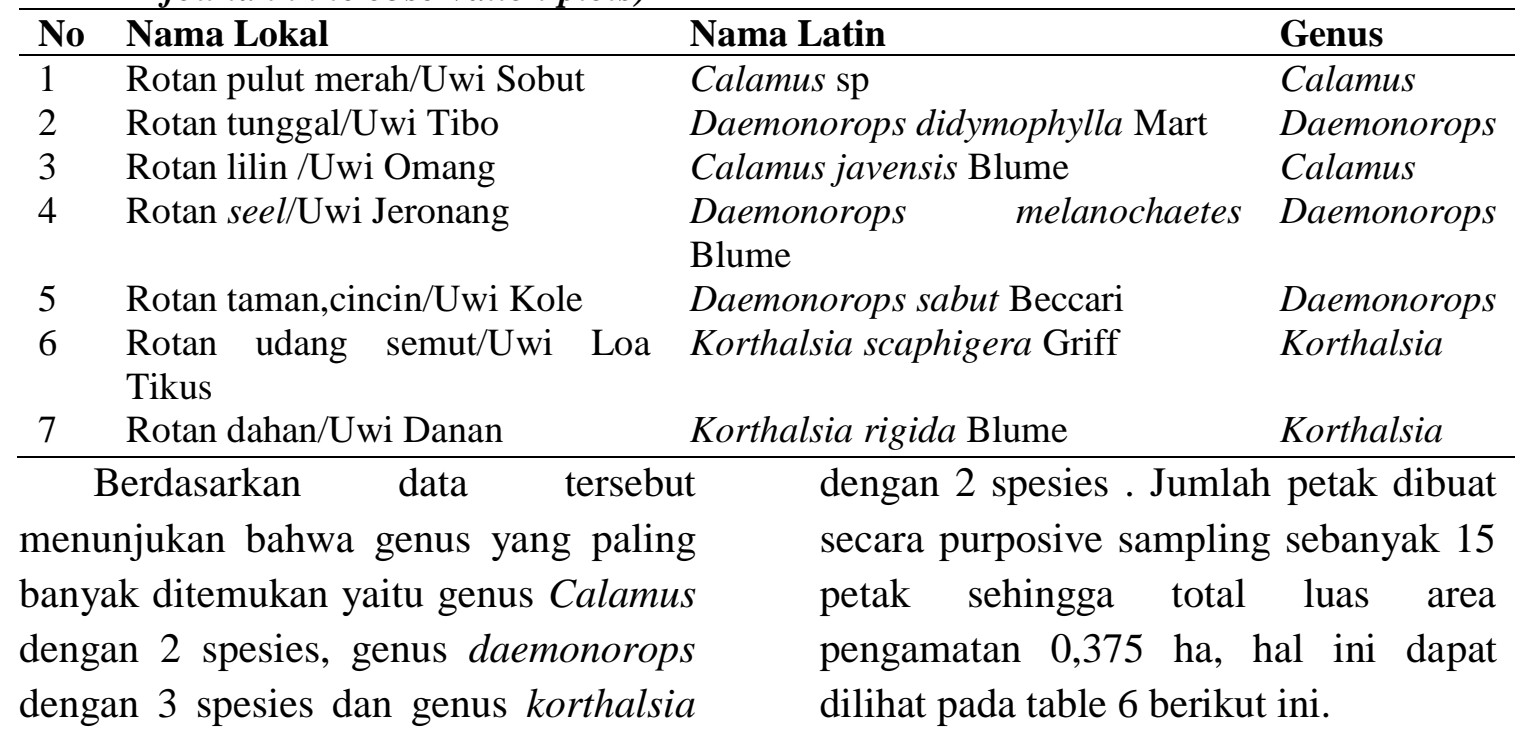


Tabel 6. Jumlah individu jenis rotan yang ditemukan pada petak pengamatan (Number of individual types of rattan found in observation plots)

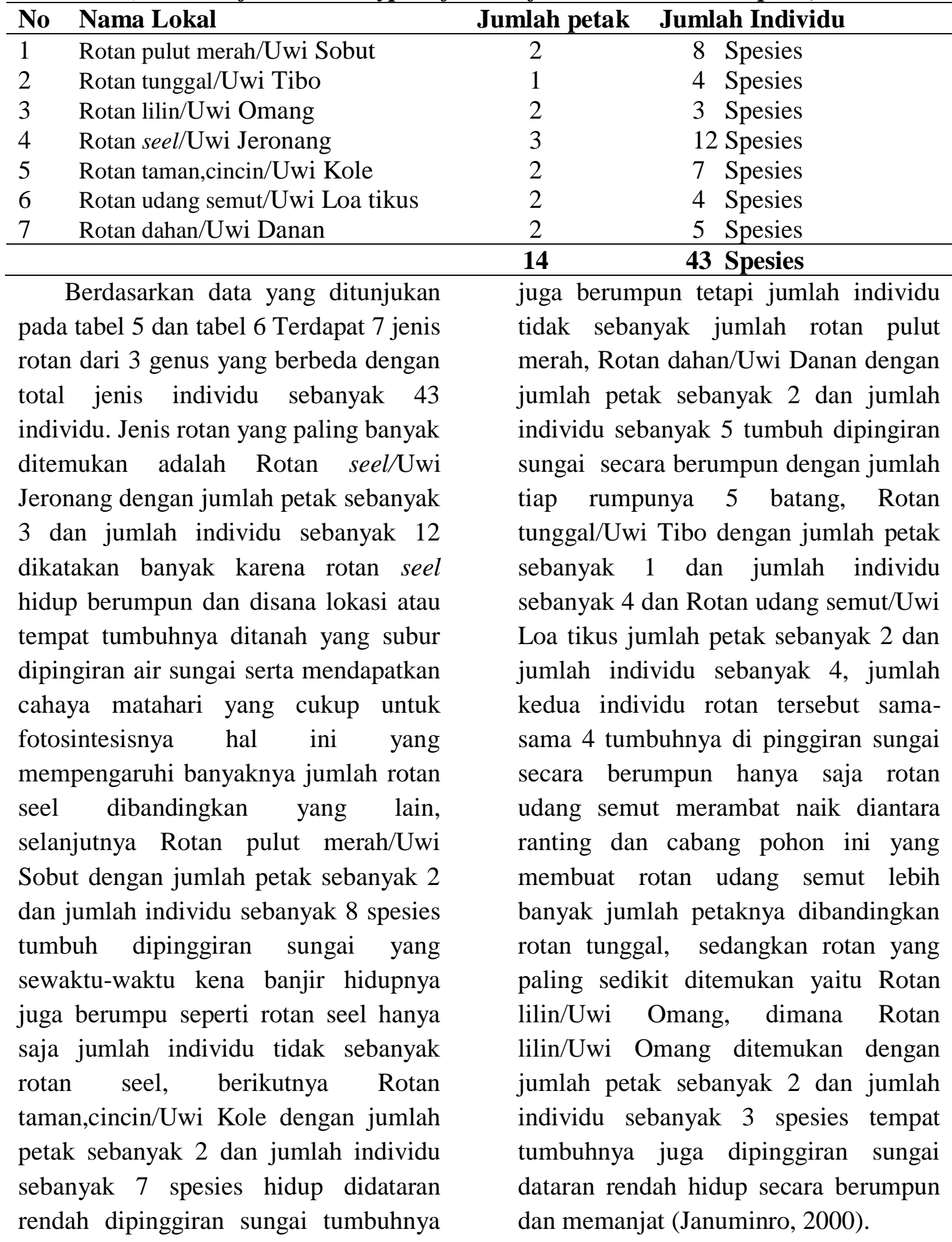




\section{Deskripsi Jenis Rotan}

\section{- Rotan Pulut Merah/Uwi Sobut (Calamus sp)}

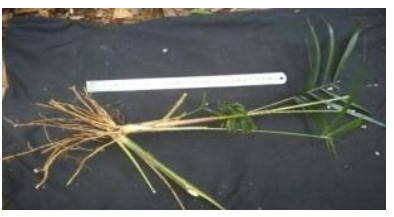

Akar

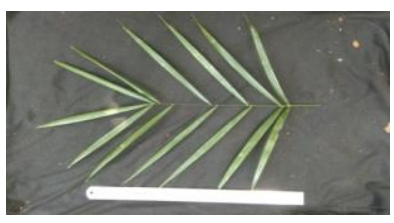

Daun

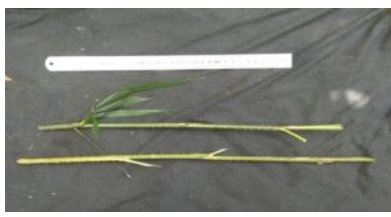

Batang

Gambar 1. Calamus sp

Terdapat didataran rendah di pinggir-pinggir sungai yang sewaktuwaktu kena banjir, tumbuh pada tanah aluvial. Hidup berumpun, tersebar di kiri kanan sungai, mudah dikembangkan dengan menggunakan anakan alam, sebagian sudah dikembangkan oleh masyarakat. Batang rotan pulut merah lebih halus dibandingkan dengan rotan irit, diameter batang 0,2-0,4 $\mathrm{cm}$, panjang batang 30 meter, jumlah batang mencapai 40 setiap rumpun, panjang ruas $40 \mathrm{~cm}$. Daun rotan pulut merah majemuk menjari, memiliki ciri khas yaitu ujung daunnya bewarna kemerahmerahan. Duri pada batang ( seludang ) dan daun berbentuk halus dan lunak. Rotan pulut merah termasuk rotan bermutu baik, sehingga banyak digunakan untuk bahan pembuatan kerajinan, khususnya anyaman, karena hasilnya baik dan indah menurut (Djamal Sanusi, 2012).

- Rotan Tunggal/Uwi Tibo (Daemonorops didymophylla Becc)

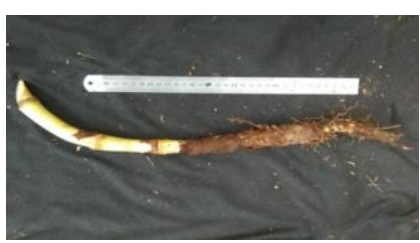

Akar

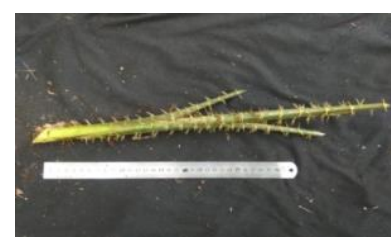

Batang

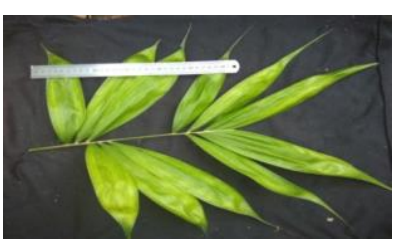

Daun

Gambar 2. Daemonorops didymophylla Becc

Rotan tunggal dijumpai pada ketinggian 10-1000 m diatas permukaan laut, terutama lembah perbukitan hutan. Rotan tunggal tumbuh secara berumpun dengan ukuran sedang. Diameter batang tanpa pelepah daun $12 \mathrm{~mm}$, dengan pelepah daun $30 \mathrm{~mm}$. Sisik buah tertutup dengan resin berwarna merah (darah naga). Buah rotan tunggal digunakan oleh masyarakat lokal sebagai obat. Mula-mula buah dikeringkan dan kemudian resinnya diambil dengan cara mengosok buah dengan cangkang tiram. Resin yang dihasilkan kemudian diproses lebih lanjut yaitu dibungkus dengan secarik kain, dilembabkan dalam air panas dan diperas. Batang rotan ini digunakan sebagai rotan belah, (Januminro, 2000). 
- Rotan Lilin/Uwi Omang (Calamus javensis Blume)

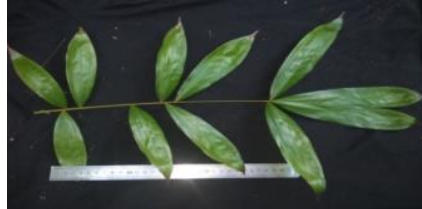

Daun

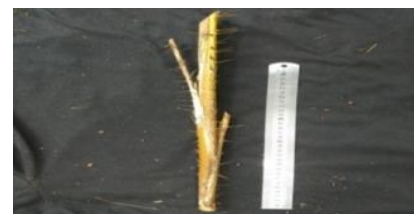

Batang

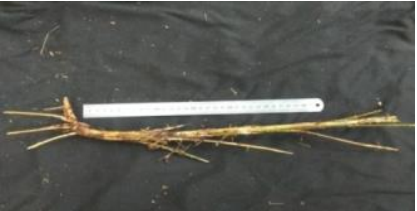

Akar

Gambar 3. Calamus javensis Blume

Rotan ini tumbuh daerah dataran rendah ataupun pegunungan sampai ketinggian $1.200 \mathrm{~m}$ diatas permukaan laut. Rotan ini tumbuh secara berumpun dan memanjat. Panjang batang dapat mencapai $50 \mathrm{~m}$. Batangnya berwarna kuning muda, tetapi akan berubah menjadi coklat kekuning-kuningan dan mengkilap apabila sudah kering. Diameter batang tanpa pelepahnya 2-6 mm dan bila bersama pelepah sampai $10 \mathrm{~mm}$. Panjang ruas buku $30 \mathrm{~cm}$ atau lebih dan panjang batang yang dapat dipungut $10 \mathrm{~m}$. Bentuk anak daun bervariasi dari lonjong bundar telur sampai lanset bundar sungsang yang ujungnya meruncing anak daun melekat dekat batang dan tumbuh ke arah batang. Panjang tangkai daun bervariasi dari pendek sekali sampai panjang 6 $\mathrm{cm}$. Tangkai daun sedikit berduri. Bunganya berbentuk malai memanjang. Bunga yang satu mandul dan berbentukn sulur yang berfungsi untuk memanjat, sedangkan bunga yang lainnya subur. Panjang bunga yang subur dan yang mandul $1 \mathrm{~m}$. Bentuk buahnya bervariasi dari bulat sampai lonjong. Panjang buah yang lonjong mencapai 1,5 m. Kulit buah bersisik dan berbiji satu. Kegunaan utama batang rotan lilin adalah untuk bahan pembuatan keranjan, pengikat, tikar, dan kerajinan anyaman lainnya, (Djamal Sanusi, 2012).

- Rotan Seel/Uwi Jeronang (Daemanorops Melanochaetes Blume)

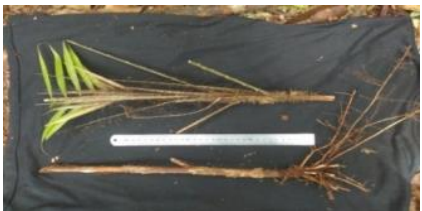

Akar

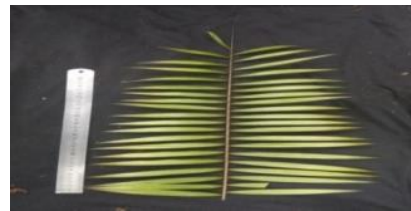

Daun

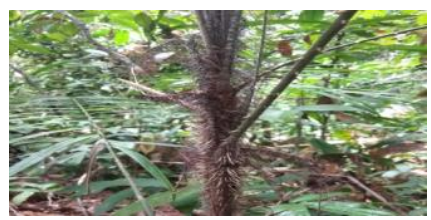

Batang

Gambar 4. Daemanorops Melanochaetes Blume

Terdapat didataran rendah sampai pegunungan dengan ketinggian tempat tumbuh $10-500 \mathrm{~m}$ di atas permukaan laut. Hidup berumpun, batang berwarna hijau kekuningan dan sesudah dirunti dan kering menjadi berwarna kuning telur. Daun berwarna kekuningkuningan, rotan seel digunakan sebagai bahan pembuatan kursi,tangkai sapu, dan bahan anyaman. Kubisnya dapat dimakan, (Djamal Sanusi, 2012). 
- Rotan Taman,Cincin/Uwi Kole (Daemonorops Sabut Beccari)

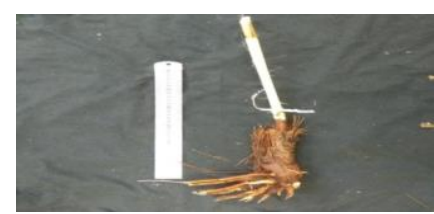

Akar

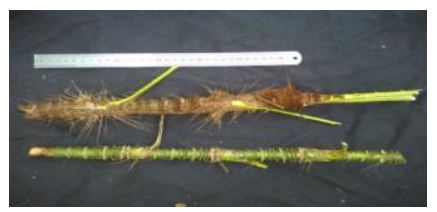

Batang

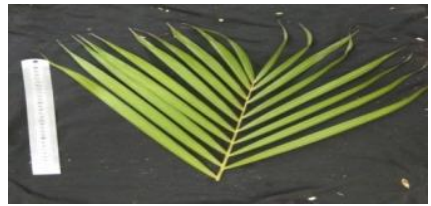

Daun

Gambar 5. Daemonorops Sabut Beccari

Terdapat didataran rendah sampai pergunungan, dipinggir sungai dengan ketinggian tempat tumbuh 100-300 m diatas permukaan laut. Jenis tanah tempat tumbuh adalah aluvial (liat berpasir). Rotan taman hidup berasosiasi dengan rotan sega, berumpun dan rumpunnya hampir sama dengan rotan sega.Batang berwarna hijau kekuningan dan setelah dirunti dan kering menjadi berwarna kuning telur. Ukuran batang dan panjang ruas hampir sama dengan rotan sega dan memiliki kelenturan yang sama dengan rotan sega, sehingga dalam dunia perdagangan dikelompokan kedalam rotan sega. Daun berbentuk seperti daun kelapa, bagian beranak daun memiliki panjang 100-200 cm, panjang sirus 50$100 \mathrm{~cm}$. Duri pelepah melingkar dan terdiri atas duri-duri panjang yang halus berwarna abu-ab, panjang duri 2-4 cm. Rotan taman banyak digunakan untuk lampit anyaman dan lain-lain, (Djamal, Sanusi, 2012).

\section{- Rotan Udang Semut/Uwi Loa Tikus (Korthalsia scaphigera Griff)}

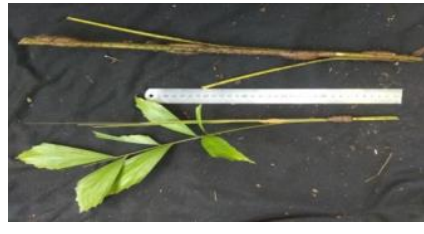

Batang

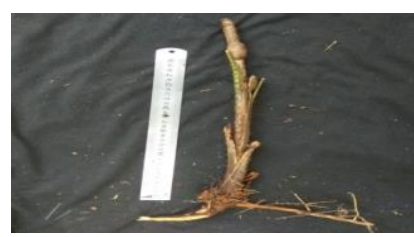

Akar

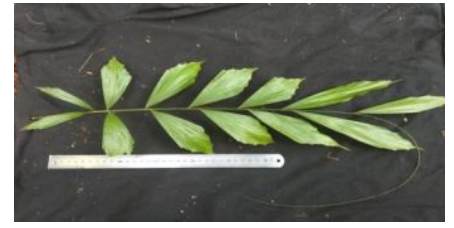

Daun

Gambar 6. Korthalsia scaphigera Griff

Rotan udang semut banyak tumbuh ditempat yang tergenang air, terutama ditepi-tepi sungai yang berawa. Rotan ini tumbuh secara berumpun dan jumlah tiap rumpun dapat mencapai 15 batang rotan ini merambat naik diantara rantin, cabang dan tajukpohon setinggi $45 \mathrm{~m}$ atau lebih. Batang yang sudah dirunti berwarna coklat kusam, bergaris membujur dan intinya berwarna kuning gading. Batang rotan ini bergaris tengah tidak lebih dari $4 \mathrm{~mm}$, bentuknya sangat merata dan panjang ruas antara 10-20 $\mathrm{cm}$. Daun berbentuk menyirip majemuk yang panjangnya mencapai $1,1 \mathrm{~m}$ termasuk sulur sepanjang $60 \mathrm{~cm}$. Anak daun berselang-seling. Jumlah anak daun pada salah satu bagian sekitar 3-7 anakn daun, panjang $27 \mathrm{~cm}$, dan lebar $10 \mathrm{~cm}$. Rotan ini dalam keadaan segar dapat dijadikan sebagai bahan pengikat yang cukup kuat dan mudah dibelah, tetapi jika telah kering mudah putus dan rapuh, (Januminro, 2000). 
- Rotan Dahan/Uwi Danan (Korthalsia rigida Blume)

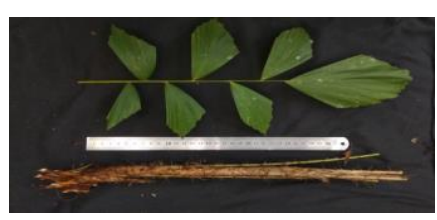

Akar

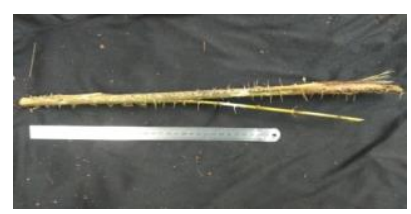

Batang

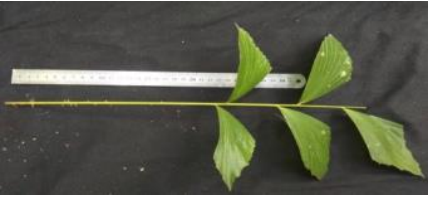

Daun

Gambar 7. Korthalsia rigida Blume

Rotan dahan banyak tumbuh di daerah dataran rendah sampai pergunungan dengan ketinggian tempat $1100 \mathrm{~m}$ di atas permukaan laut. Rotan dahan tumbuh secara berumpun dan jumlah tiap rumpun sekitar 5 batang. Panjang batang mencapai $20 \mathrm{~m}$ atau lebih, diameter batang yang sudah dibersihkan rata-rata $20-25 \mathrm{~mm}$ dan panjang ruas buku $20 \mathrm{~cm}$. Bentik batang tidan rata dan buku-bukunya menonjol. Warna batang coklat kusam dan intinya bewarna coklat muda. Panjang daun rotan dahan mencapai $1,5 \mathrm{~m}$, termasuk tangkai daun $10 \mathrm{~cm}$ dan sulur panjat 75 $\mathrm{cm}$. Bentuk daun menyirip majemuk, sedangkan anak daun berbentuk belah ketupat yang menempel secara berselang-seling. Batang rotan dahan mudah dibelah dan biasanya digunakan sebagai bahan pembuatan keranjang, (Januminro, 2000).

\section{Kesimpulan}

1. Ditemukan sebanyak 7 jenis dengan 3 genus berbeda dengan total keseluruhan 43 individu.

2. Jenis-jenis yang ditemukan ialah Rotan Udang Semut/Uwi Loa Tikus (Korthalsia scaphigera Griff), Rotan Seel/Uwi Jeronang (Daemanorops Melanochaetes Blume), Rotan Tunggal/Uwi Tibo (Daemonorops didymophylla Becc), Rotan Pulut
Merah/Uwi Sobut (Calamus sp), Rotan Lilin/Uwi Omang (Calamus javensis Blume), Rotan Taman,Cincin/Uwi Kole (Daemonorops Sabut Beccari), dan Rotan Dahan/Uwi Danan (Korthalsia rigida Blume).

3. Jenis yang ditemukan di dominasi oleh genus Daemonorops paling banyak (3 jenis dengan 23 individu), diikuti oleh genus Calamus (2 jenis dengan 11 individu), Genus Korthalsia (2 jenis dengan 9 individu).

\section{Saran}

1. Pentingnya usaha untuk menjaga dan mempertahankan kelestarian sumber daya alam yang ada pada daerah Kecamatan Jangkang Kawasan Hutan Adat Dusun Ensibau Desa Semirau Kabupaten Sanggau khususnya jenis-jenis rotan, maka diharapkan pada seluruh Instansi terkait agar dapat memberikan perhatian yang sangat sungguhsungguh terhadap pelestarian sumber daya alamini.

2. Mengingat masih adanya aktifitas masyarakat disekitar Kawasan Hutan Adat Dusun Ensibau Desa Semirau Kabupaten Sanggau khususnya Kecamatan Jangkang yang dimanfaatkan sumber daya alam 
yang ada untuk berbagai keperluan, maka perlu suatu penangganan upaya yang tepat dan efektif, agar masyarakat yang memanfaatkan sumber daya alam pada daerah ini bertanggung jawab.

3. Perlu adanya peremajaan rotan agar jenis-jenis yang ada tidak punah dan dapat terus dilestarikan.

DAFTAR PUSTAKA

Januminro CFM. 2000. Rotan Indonesia. Kansius, Yokyakarta.

Jumiati, 2012.Studi Etno botani Rotan Sebagai Bahan Kerajinan
Ayaman Pada Suku Anak Dalam (SAD) Di Dusun III Senami, Desa Jebak, Kabupaten Batang hari, Jambi. Jurnal Biospecies Vol. 5 No.1, Febuari 2012.

Djamal Sanusi. 2012. Rotan Kekayaan Belantara Indonesia. Brilian Internasional, Surabaya.

Sardana A. Julinda H. Nyoman G G Y D. Arfian E N. Neneng A.2011. Potret Hutan Propinsi Kalimantan Barat. Kementrian Kehutanan Direktorat Jendral Kehutanan, Balai Pemantapan Hutan Wilayah III Pontianak. 